\title{
1981 VON HIPPEL AWARD ADDRESS
}

Highlights from the Von Hippel Award remarks of Prof. James W. Mayer, Cornell University.

I am honored to be the recipient of the Von Hippel Award. Prof. Von Hippel's long-standing, interdisciplinary approach to the science and engineering of materials exemplifies the spirit of the Materials Research Society today. The award has a special significance to me because of my research associated with a previous award recipient, David Turnbull, and two MRS presidents, John Poate and King Nung Tu. Prof. Turnbull and his group at Harvard have been a source of inspiration to my colleagues and to me over the past ten years in our investigation of epitaxial growth both in the solid phase and in the transient liquid-phase. David Turnbull has a delightful touch with his pocket slide-rule. King Tu has developed my awareness of the materials science aspects of thin-film reactions in our long association in studies of silicides. John Poate provided the impetuous for ion-beam mixing through our work on preferential sputtering of silicides and implantation in copper single crystals. My years at Caltech are linked with Marc Nicolet, my associate in many ventures, and with students and colleagues such as S. S. Lau, who provided the excitement in our studies. The Von Hipple Award is also recognition of the contributions of all these associates and colleagues.

This is an exciting time to be involved in materials research, as witnessed by the attendance at this meeting of the Materials Research Society. From the viewpoint of Prof. Von Hippel, it has always been an exciting time. I draw from his book The Molecular Designing of Materials and Devices (M.I.T. Press, 1965) that comprises publications from lecturers at his 1963 summer session course at the MIT Laboratory for Insulation Research. It is a provocative book, as provocative as C. Escher's "Thinker", which appears as the first illustration in the book, and reflects Von Hippel's view that the "isolation of specialists is ending" and that they are drawn into "mutual alliance" to "create any kind of material and device". In my research the present thrust of materials science follows the same course as outlined nearly twenty years ago but with emphasis on tailoring the outer microns of material and on understanding surfaces and interfaces. This focus arises naturally because of the development of high-vacuum techniques and analytical tools such as auger electron spectroscopy, secondary-ion-mass spectrometry and Rutherford backscattering, which measure composition depth profiles. One has the tools, now, to study surfaces, interfaces and thin-film reactions. Ion implantation, ionbeam mixing, and pulsed beams lasers, electrons and ions - allow tailoring of the composition and structure of the near surface region.

We are truly at the forefront of a field that will establish the technology for future devices and structures. In spite of this, we face difficult times. Funds for the basic research that is at the heart of materials science are being cut. The atmosphere is reflected in headlines ..." Cuts in U.S. Research Support Batter National Laboratories"... "Scientists Warn White House About Dangers of Cuts in Basic Research"... "Budget Cuts"... "Frank Press to American Science: 'Tell People What You're Doing and Why It Is Important"... "Reduction in Funds for Research and Development".

These cuts are not a new phenomenon; I experienced them twice before in the early 60's and 70 's. Now, however, research in the modification and analysis of surfaces and interfaces is even more expensive. Research systems cost between $\$ 100,00$ to $\$ 500,000$. At universities, even burdened costs of graduate students are about $\$ 20,000 /$ year.

I believe that we cannot rely on government funds to carry out our research programs and I suggest direct collaboration of University with Industry. In this approach, industrial laboratories would give a grant or contract directly to a university department for work in a fairly specific area of research. This would have the advantage that industrial groups would have back-up research underway in areas of direct interest; this support would also have an altruistic flavor as it would provide for the training of graduate students. From the standpoint of the university department or professor it would provide clearly identified support.

At present, there is industrial support of universities as well as fellowship programs and research contracts. My proposal is to strengthen the ties between university and industrial researchers on a direct basis. There are problems with this approach involving both the time scale and patents. University research is not geared to "fire-fights" on the production line and the research must be open and publishable. The patent situation has both University and Industry claiming their rights. One solution is to have the research cover broad areas that do not involve proprietary processes and to share the patents by assigning the licensing rights to the corporation and by splitting the royalties on a mutually agreed basis.

We must cooperate - University and Corporation - if we are to maintain our technological base at the forefront of materials science. It is too exciting an area to neglect. 